\title{
Origin of the large electrostrain in BiFeO3-BaTiO3 based lead-free ceramics
}

DOI:

10.1039/C9TA07904A

Document Version

Accepted author manuscript

Link to publication record in Manchester Research Explorer

\section{Citation for published version (APA):}

Wang, G., \& Hall, D. (2019). Origin of the large electrostrain in BiFeO3-BaTiO3 based lead-free ceramics. Journal of Materials Chemistry A, 7, 21254-21263. https://doi.org/10.1039/C9TA07904A

\section{Published in:}

Journal of Materials Chemistry A

\section{Citing this paper}

Please note that where the full-text provided on Manchester Research Explorer is the Author Accepted Manuscript or Proof version this may differ from the final Published version. If citing, it is advised that you check and use the publisher's definitive version.

\section{General rights}

Copyright and moral rights for the publications made accessible in the Research Explorer are retained by the authors and/or other copyright owners and it is a condition of accessing publications that users recognise and abide by the legal requirements associated with these rights.

\section{Takedown policy}

If you believe that this document breaches copyright please refer to the University of Manchester's Takedown Procedures [http://man.ac.uk/04Y6Bo] or contact uml.scholarlycommunications@manchester.ac.uk providing relevant details, so we can investigate your claim.

\section{OPEN ACCESS}




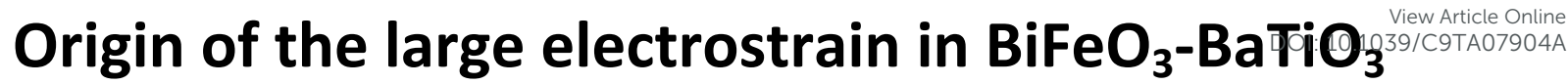 based lead-free ceramics
}

Ge Wang, ${ }^{a}$ Zhongming Fan, ${ }^{b}$ Shunsuke Murakami, ${ }^{a}$ Zhilun Lu, ${ }^{a}$ David. A. Hall, ${ }^{c}$ Derek. C. Sinclair, ${ }^{a}$ Antonio Feteira, ${ }^{d}$ Xiaoli Tan, ${ }^{b}$ Jacob. L. Jones, ${ }^{e}$ Annette K. Kleppe, ${ }^{f}$ Dawei Wang $^{a^{*}}$ and Ian. M. Reaneya

a. Department of Materials Science and Engineering, University of Sheffield, Sheffield S1 3JD, UK.

b. Department of Materials Science and Engineering, lowa State University, Ames, IA 50011, USA.

c. School of Materials, University of Manchester, Manchester, M13 9PL, UK.

d. Materials and Engineering Research Institute, Sheffield Hallam University, Sheffield S1 1WB, UK.

e. Department of Materials Science and Engineering, North Carolina State University, Raleigh, NC, 27695, USA

f. Diamond Light Source Ltd, Harwell Science and Innovation Campus, Didcot, OX11 ODE, UK.

*Corresponding author: email: dawei.wang@sheffield.ac.uk

\begin{abstract}
High electrostrain and breakdown strength, (1-x) $\mathrm{BiFeO}_{3}-0.3 \mathrm{BaTiO}_{3}-\mathrm{xNd}\left(\mathrm{Li}_{0.5} \mathrm{Nb}_{0.5}\right) \mathrm{O}_{3}(\mathrm{BF}-$ BT-xNLN) ceramics were studied by in-situ synchrotron X-ray diffraction (XRD) in combination with Rietveld refinement and conventional transmission electron microscopy. At zero field, compositions transformed from majority ferroelectric rhombohedral to pseudocubic as the NLN concentration increased, with $0.27 \%$ strain achieved at $60 \mathrm{kV} \mathrm{cm}^{-1}$ for $x=0.01$. The large measured macroscopic strain was commensurate with peak shifting in XRD peak profiles, yielding $0.6 \%$ total strain at $150 \mathrm{kV} \mathrm{cm}^{-1}$. Strain anisotropy of $\varepsilon_{200}>$ $\varepsilon_{220}>\varepsilon_{111}$ was observed but despite the large applied field, no peak splitting was detected. We therefore conclude that the large electrostrain is not achieved through a conventional relaxor to field induced long-range ferroelectric transition. Instead, the data supports a model where local polar regions distort in the direction of the applied field within multiple local symmetries (pseudosymmetry) without long range correlation. We propose that pseudosymmetry is maintained in BF-BT-xNLN even at high field $\left(150 \mathrm{kV} \mathrm{cm}^{-1}\right)$ due to the large ion radii mismatch and competing ionic/covalent bonding between $\mathrm{Ba}^{2+}$ and $\mathrm{Bi}^{3+}$ ions.
\end{abstract}

Keywords: local polar distortion; synchrotron x-ray diffraction; electro-strain; bismuth ferrite; piezoelectric ceramics 


\section{Introduction}

Bismuth ferrite (BF)-based solid solutions are considered candidates as lead-free functional ceramics due to their promising ferroelectric (FE) properties [1]. Among various BF-based solid solutions, (1-x) $\mathrm{BiFeO}_{3}-\mathrm{xBaTiO}{ }_{3}$ (BF-BT) has attracted attention for compositions within or close to a mixed phase region (MPR) in which rhombohedral and cubic polymorphs coexist. These compositions have high ferroelectric Curie temperature $\left(T_{c}>400^{\circ} \mathrm{C}\right)$ but are also reported to have large remanent $\left(P_{r}\right)$ and saturation $\left(P_{s}\right)$ polarisation coupled with large piezoelectric coefficients $\left(d_{33}\right)$, particularly for samples quenched from the sintering temperature $[2,3]$.

More importantly, large electric field-induced (E-induced) strains and strain coefficients $\left(\mathrm{d}_{33}{ }^{*}\right)$ have been extensively reported in doped (1-x)BF-xBT within the MPR for $0.25 \leq x \leq 0.35$. For example, butterfly-shaped strain-electric field (S-E) loops are obtained for $x=0.25$ and 0.3 ceramics that exhibit $\sim 0.1$ and $0.26 \%$ strain under 70 and $100 \mathrm{kV} \mathrm{cm}^{-1}$, respectively [4]; however, substituting $0.5 \% \mathrm{Bi}\left(\mathrm{Zn}_{2 / 3} \mathrm{Nb}_{1 / 3}\right) \mathrm{O}_{3}$ results in larger value of strains ( $0.43 \%, \mathrm{~d}_{33}{ }^{*} \sim$ $\left.424 \mathrm{pm} \mathrm{V}^{-1}\right)$ under equivalent fields $\left(100 \mathrm{kV} \mathrm{cm}^{-1}\right)$. [5] The substitution of a third component (often a nominal perovskite composition) in the solid solution, results in an FE to relaxorferroelectric (RFE) phase transition and enhances strain [6, 7]. So far, the highest $d_{33}{ }^{*} \sim 544$ pm V-1 with strain $\sim 0.27 \%$ at $50 \mathrm{kV} \mathrm{cm}^{-1}$ was obtained for BF-0.3BT doped with $5 \% \mathrm{Bi}\left(\mathrm{Mg}_{2 / 3} \mathrm{Nb}_{1 / 3}\right) \mathrm{O}_{3}$, which also exhibited good temperature stability up to $\sim 175^{\circ} \mathrm{C}$. [8]

Optimized electrostrain in BF-BT is typically achieved by stoichiometric doping on the A/B sites, shifting the phase assemblage from majority FE to mixed FE/RFE to RFE as doping concentration increases. However, the detailed mechanism behind the large strain in BF-BTbased materials is not well understood with only a few limited studies performed. For example, a comparison between unpoled and poled 0.75BF-0.25BT ceramics was carried out "ex-situ" using high-resolution transmission electron microscopy (HRTEM). [9] A mix of nanodomains and long-range ordered rhombohedral FE domains was observed for the unpoled and poled states [9] but this composition was not optimised for strain and already dominantly FE, prior to poling. High-energy synchrotron X-ray diffraction (XRD) $[10,11]$ in-situ electric field poling experiments have also been performed on 0.67BF-0.33BT and 0.6BF-0.3BT-0.1Bi $\left(\mathrm{Mg}_{1 / 2} \mathrm{Ti}_{1 / 2}\right) \mathrm{O}_{3}$. The crystal structure remained pseudocubic prior, during and after application of electric field, characterised by single $\{110\}_{p},\{111\}_{p}$ and $\{200\}_{p}$ XRD reflections. More recently, in-situ poling of La-doped $0.75 \mathrm{BF}-0.25 \mathrm{BT}$ ceramics was carried out to confirm the contribution of both lattice strain and domain switching to total estimated strain. [12] However, experimental S-E results were not reported, hence the results were uncorrelated with the estimated strain obtained from their in-situ XRD studies. [12]

The aim of the present study is to investigate the origin of the large electrostrain using in-situ poling synchrotron XRD in BF-BT-based materials optimised for $\mathrm{d}_{33}{ }^{*}$. The estimated strain from peak shifts is compared against S-E measurements and a new model for the origin of the large $\mathrm{d}_{33}{ }^{*}$ and high strain in BF-BT systems proposed. Highly active regions with multiple local symmetries (pseudosymmetry) align with the applied field but do not coalesce into a single symmetry, long-range ordered FE state, due to competition between ionic and covalent bonding of the $\mathrm{Ba}^{2+}$ and $\mathrm{Bi}^{3+}$ ions and mismatch of their ionic radii. 


\section{Experimental}

(1-x) $\mathrm{BiFeO}_{3}-0.3 \mathrm{BaTiO}_{3}-\mathrm{xNd}\left(\mathrm{Li}_{0.5} \mathrm{Nb}_{0.5}\right) \mathrm{O}_{3}$ (BF-BT-xNLN, $\left.0 \leq \mathrm{x} \leq 0.05\right)$ ceramics were synthesized using solid-state reaction. Analytical-grade $\mathrm{BaCO}_{3}, \mathrm{Fe}_{2} \mathrm{O}_{3}, \mathrm{Bi}_{2} \mathrm{O}_{3}, \mathrm{TiO}_{2}, \mathrm{Nd}_{2} \mathrm{O}_{3}, \mathrm{Li}_{2} \mathrm{CO}_{3}$ and $\mathrm{Nb}_{2} \mathrm{O}_{5}$ powders were weighed in the appropriate stoichiometric proportions and balled milled for 16 h. After calcination, 0.1 wt\% of $\mathrm{Mn}_{2} \mathrm{O}_{3}$ was added, followed by further milling for $16 \mathrm{~h}$. Powders were dried, uniaxially pressed into $10 \mathrm{~mm}$ diameter pellets and sintered for $2 \mathrm{~h}$ at 980-1070 ${ }^{\circ} \mathrm{C}$ in air $[4,5]$. The density of the sintered ceramics was measured using the Archimedes method. Surfaces of as-sintered ceramics were ground and silver paste electrodes applied. P-E and S-E loops were obtained using an aixACCT TF 2000E ferroelectric tester at 1 $\mathrm{Hz}$. Temperature-dependent dielectric properties were measured using an Agilent 4184A precision LCR meter from room temperature (RT) to $600{ }^{\circ} \mathrm{C}$ at $1,10,100$ and $250 \mathrm{kHz}$.

An FEl Tecnai G2-F20 transmission electron microscopy (TEM) and operated at $200 \mathrm{kV}$ was employed for TEM observation. The TEM specimen with a $3 \mathrm{~mm}$ diameter was prepared through mechanical dimpling, followed by low-voltage Ar ion-milling to perforation.

In-situ poling high-energy synchrotron XRD experiments were performed at I15 Diamond light source with a photon energy of $72 \mathrm{keV}(0.1722 \AA)$. Prior to in-situ XRD experiments, ceramic discs were ground, gold sputtered on two sides to form electrodes, cut into bars $(8 \times 0.5 \times$ $0.5 \mathrm{~mm}$ ) and annealed for $4 \mathrm{~h}$ at $700{ }^{\circ} \mathrm{C}$ to eliminate residual stresses. The $\mathrm{X}$-ray beam was focussed and collimated to $70 \mu \mathrm{m}$ in diameter directly in front of the sample. The bar-shape specimens were placed in silicone oil in a custom-designed polyimide sample holder. During in-situ poling measurements, the sample holder was electrically connected with a high voltage amplifier (Matsusada EC-10). In-situ XRD was carried out in transmission and 2-D diffraction patterns were collected using a Perkin-Elmer XRD 1621 flat-panel detector located approximately 1 metre downstream of the sample. Collected images were converted into conventional one-dimensional XRD patterns corresponding to a range of grain orientations ( $\beta$ ) relative to the poling direction with a step size of $15^{\circ}$ using Dawn software. [13] Fitting of selected diffraction peaks was carried out using Topas 5 software. [14] Diffraction patterns with $\beta=0$ or $\beta=90^{\circ}$ were obtained, parallel and perpendicular, respectively, to the electric field to determine longitudinal and transverse strain behaviour. [15]

\section{Results and discussion}

\section{Full-pattern Rietveld refinement and transmission electron microscopy (zero field)}

Full pattern Rietveld refinement was performed for all compositions in the unpoled state with the best fits being obtained using rhombohdral $(R 3 c)$ and cubic $(P m \overline{3} m)$ phases, as previously reported for other BF-BT compositions. [16-18], A mixed-phase of rhombohedral (62\%) and cubic (38\%) polymorphs was obtained for BF-0.3BT, yielding excellent GOF 1.19, as shown in Figure 1 which illustrates the $\{111\}_{p},\{200\}_{p},\{211\}_{p}$ and $\{220\}_{p}$ peaks. As a result of the majority $R 3 c$ phase, FE P-E and S-E loops were obtained from BF-0.3BT ceramics with $\mathrm{x}<0.03$, as shown in Supplementary Information, Figure S1. 


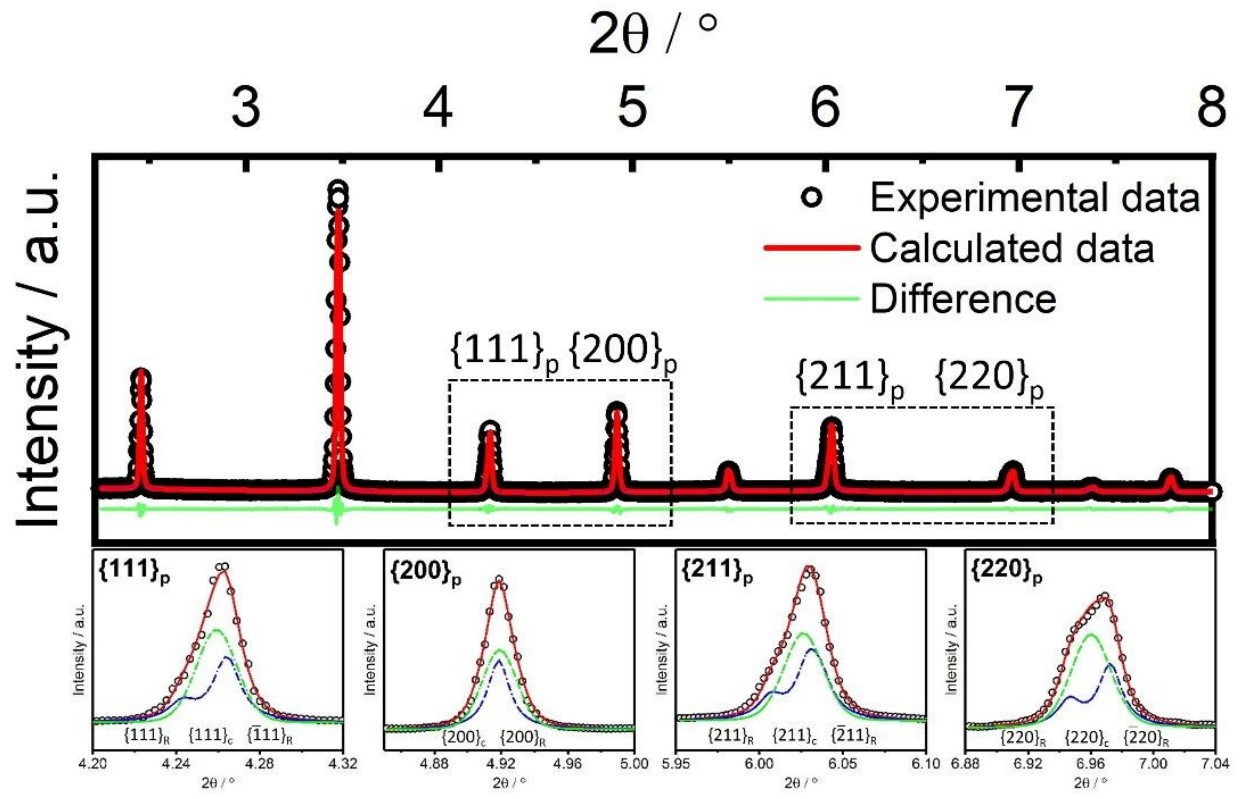

Figure 1. High energy synchrotron XRD pattern and corresponding Rietveld refinement results for the unpoled BF-0.3BT ceramic with contributions of rhombohedral $(R 3 c)$ and cubic $(P m \overline{3}$ $m$ ) phases to individual peak profiles in the calculated pattern.

For $x=0.01$, the MPR becomes majority cubic $(63 \%)$ and minority rhombohedral phase (37\%), resulting in a pronounced shift in the position of the peak in the $\varepsilon_{\mathrm{r}}$-T plots as a function of frequency (Supplementary information, Figure S2). For $x>0.01$ a dominant cubic phase is evident in the refined data, shown in Figure 2, with commensurate reductions in polarisation and strain. (Supplementary information, Figure S1). The crystallographic parameters obtained from the Rietveld refinements for all compositions in BF-BT-xNLN are summarized in Table 1.

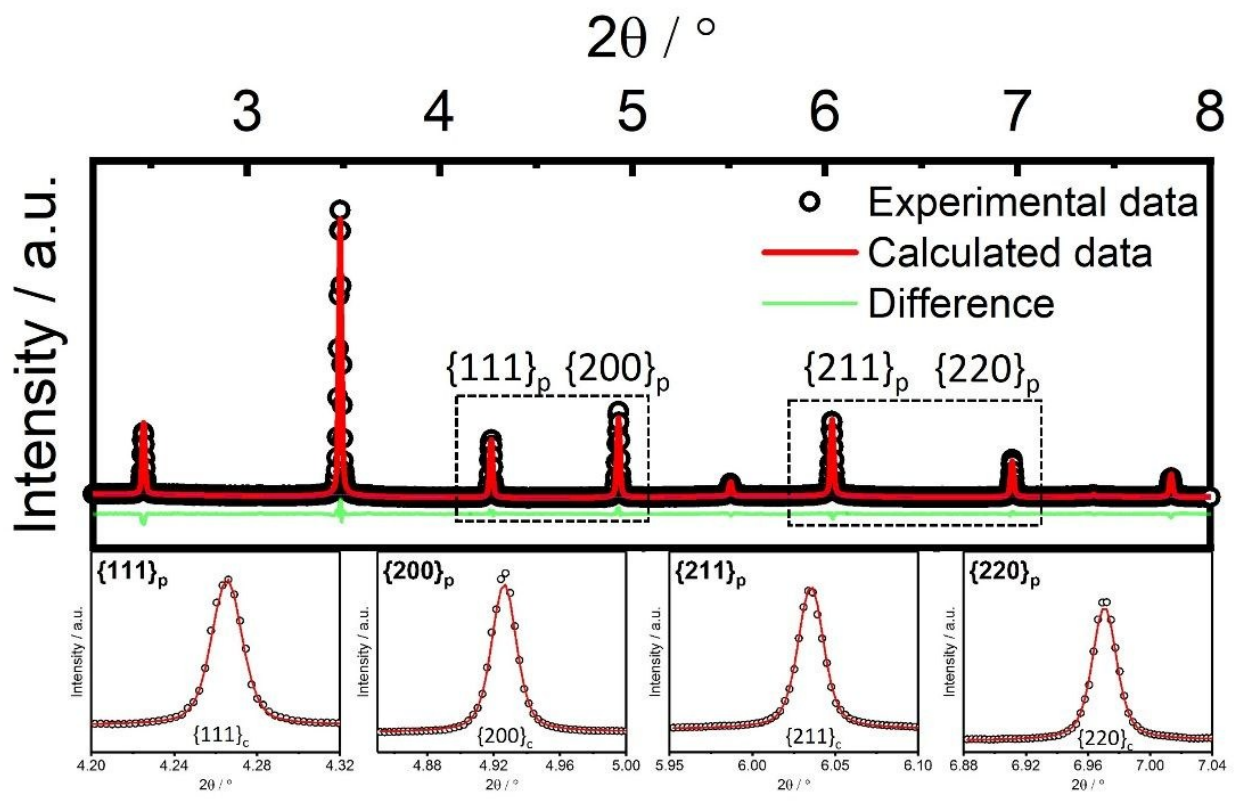


Figure 2. High energy synchrotron XRD pattern and corresponding Rietveld refinement resulttsiew Article Online for the unpoled BF-0.3BT-0.03NLN ceramic with a single cubic $(P m \overline{3} m)$ phase indexed to individual peak profiles in the calculated pattern.

Table 1. Summary of results obtained from Rietveld refinement of XRD for BF-0.3BT-xNLN ceramics. ${ }^{*} \mathrm{R}: R 3 c$ phase, $\mathrm{C}: P m \overline{3} m$ phase, GOF: goodness of fitting

\begin{tabular}{|c|c|c|c|c|c|c|c|c|c|c|}
\hline \multirow{3}{*}{$x$} & \multicolumn{2}{|c|}{ Phases / \% } & \multicolumn{3}{|c|}{ Lattice parameter } & \multicolumn{2}{|c|}{ Cell volume } & \multirow{3}{*}{$\mathbf{R}_{\mathrm{wp}}$} & \multirow{3}{*}{$\mathbf{R}_{\text {exp }}$} & \multirow{3}{*}{ GOF } \\
\hline & \multirow{2}{*}{ R } & \multirow{2}{*}{ C } & \multicolumn{2}{|c|}{$\mathrm{R}$} & \multirow{2}{*}{$\frac{C}{a / \AA}$} & \multirow{2}{*}{$R / \AA^{3}$} & \multirow{2}{*}{$C / \AA^{3}$} & & & \\
\hline & & & $\mathrm{a} / \AA$ & $c / \AA$ & & & & & & \\
\hline 0 & 62 & 38 & $\begin{array}{c}5.6608(2 \\
1\end{array}$ & $\begin{array}{c}13.9445( \\
9)\end{array}$ & $\begin{array}{c}4.0098( \\
1) \\
\end{array}$ & $\begin{array}{c}386.9 \\
8(1) \\
\end{array}$ & $\begin{array}{c}64.47 \\
(6) \\
\end{array}$ & 4.03 & 3.40 & 1.19 \\
\hline 0.005 & 55 & 45 & $\begin{array}{c}5.6615(1 \\
0)\end{array}$ & $\begin{array}{c}13.9461( \\
2)\end{array}$ & $\begin{array}{l}4.0115( \\
9)\end{array}$ & $\begin{array}{c}387.2 \\
5(3) \\
\end{array}$ & $\begin{array}{c}64.55 \\
(1)\end{array}$ & 5.16 & 3.74 & 1.38 \\
\hline 0.01 & 37 & 63 & $\begin{array}{c}5.6638(4 \\
1\end{array}$ & $\begin{array}{c}13.9470( \\
8)\end{array}$ & $\begin{array}{c}4.0130( \\
7)\end{array}$ & $\begin{array}{l}387.4 \\
7(10)\end{array}$ & $\begin{array}{c}64.62 \\
(5)\end{array}$ & 5.63 & 3.69 & 1.52 \\
\hline 0.02 & 8 & 92 & $\begin{array}{c}5.6716(6 \\
1\end{array}$ & $\begin{array}{c}13.9075( \\
13)\end{array}$ & $\begin{array}{c}4.0035( \\
7)\end{array}$ & $\begin{array}{c}387.4 \\
3(4)\end{array}$ & $\begin{array}{c}64.42 \\
(9)\end{array}$ & 6.37 & 4.20 & 1.51 \\
\hline 0.03 & 0 & 100 & $\mathrm{~N} / \mathrm{A}$ & $\mathrm{N} / \mathrm{A}$ & $\begin{array}{l}4.0034( \\
5)\end{array}$ & \begin{tabular}{|l}
383.1 \\
$9(10)$
\end{tabular} & $\begin{array}{c}64.17 \\
\text { (3) }\end{array}$ & 3.60 & 4.53 & 1.26 \\
\hline
\end{tabular}

The domain structure for BF-BT-xNLN ( $x=0.00,0.01$ and 0.03$)$ ceramics was examined using diffraction contrast TEM, Figure 3 . Undoped BF-BT ceramic has a complex domain morphology due to the existence of mixed phase, Figure 3a. Tweed domains are most commonly observed while some larger wedge-shaped domains are also present (area 1 and 2). The $R 3 c$ structure is evidenced by the appearance of $1 / 2\{000\}$ superlattice diffraction spots which arise due to antiphase tilting of the O-octahedra. The presence of an $R 3 C$ structure and domains is consistent with the refinement data shown in Table 1 and the P-E and S-E loops in Figure S1 (Supplementary information). For $\mathrm{x}=0.01$, most tweed domains as well as larger wedgeshaped domains are absent, Figure $3 \mathrm{~b}$. Instead, the BF-0.3BT-0.01NLN exhibits a core-shell structure composed of small tweed domains (core, R3C) and nanodomains (shell, cubic), consistent with structural refinements (Table 1), narrower P-E loops and a reduction in negative strain, Figure S1. For BF-0.3BT-0.03NLN (Figure 3c), only nanodomains are observed, commensurate with a pseudocubic structure (Table 1), narrow P-E and S-E loops characteristic of a relaxor, Figure S1. Moreover, $1 / 2\{000\}$ superstructure reflections associated with the R3c phase are absent. To further investigate the effect of applied field on the structure BF-BT-NLN ceramics, in-situ poling experiments were undertaken initially at $60 \mathrm{kV} \mathrm{cm}^{-1}$ (typically used to obtain S-E loops) and also at $150 \mathrm{kV} \mathrm{cm}^{-1}$ which is $\sim 2-3$ times higher than that commonly used to obtain $d_{33}{ }^{*}$ in BF-BT based ceramics. 

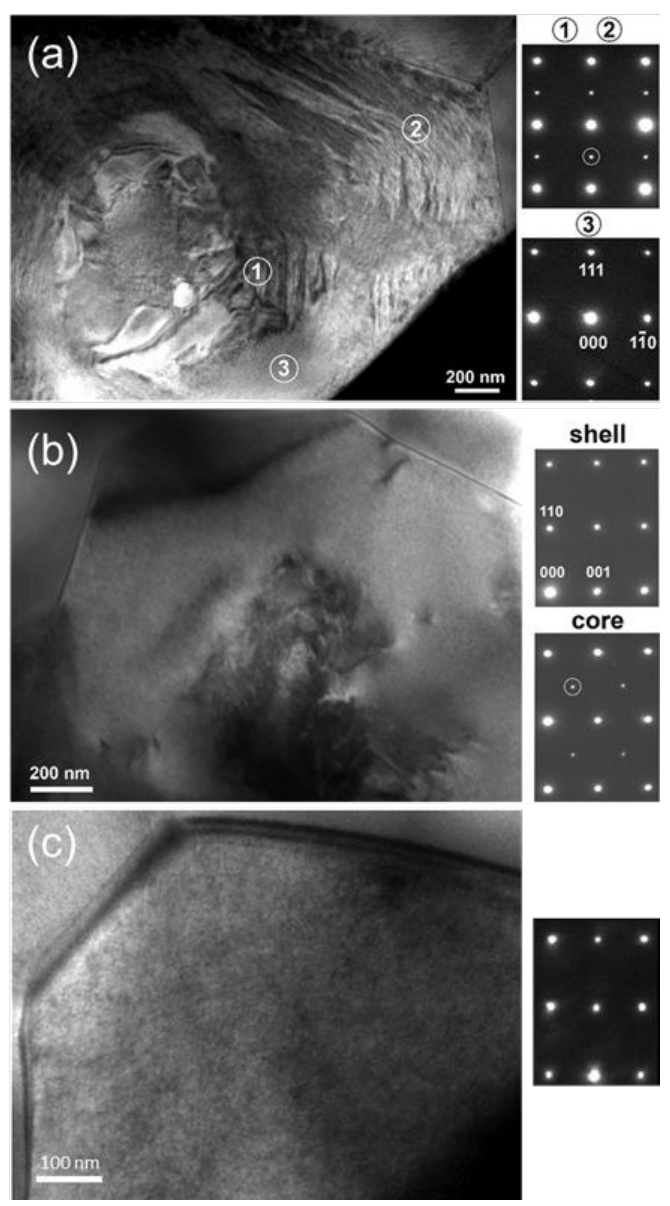

Figure 3. TEM domain morphology with diffraction spots for (a) BF0.3BT, (b)BF-0.3BT-0.01NLN and (c) BF-0.3BT-0.03NLN ceramics.

\section{In-situ poling synchrotron $\mathrm{x}$-ray diffraction $\left(60 \mathrm{kV} \mathrm{cm}^{-1}\right)$}

In bulk ceramics, direct evidence of the behaviour of the peaks, or strains, can be obtained using high energy in-situ x-ray diffraction to investigate E-induced structural transformation, domain switching and lattice deformation. Macroscopic structural transformations in perovskites are characterised by changes in $\{111\}_{p}$ and $\{200\}_{p}$ peak profiles prior to and after application of the field. [19-25] Initially, in this contribution, the macroscopic strain is evaluated by observation of $\{111\}_{p},\{200\}_{p}$ and $\{220\}_{p}$ peaks at $60 \mathrm{kV} \mathrm{cm}^{-1}$ with a step of $5 \mathrm{kV}$ $\mathrm{cm}^{-1}$. [12, 19] Measurements parallel $\left(\beta=0^{\circ}\right)$ and perpendicular $\left(\beta=90^{\circ}\right)$ to the direction of the field illustrate any domain re-orientation and associated lattice strain. The strain is calculated using $\{111\}_{p},\{200\}_{p}$ and $\{220\}_{p}$ diffraction peaks and quantified using an effective average lattice spacing, $d_{\mathrm{hkl}}$ for $\beta=0$ and $90^{\circ}$. With contribution from electrostrain response, e.g. electrostriction and/or piezoelectricity, here the transverse strains are negative (compressive) and the longitudinal strains are positive (tensile), respectively.

Peak profile fitting was performed in Matlab using a pseudo-Voigt function and the effective lattice strain under different electric fields for different Miller indices (hkl) estimated using the lattice spacings corresponding to the unpoled reference state, $d_{h k l}(u n)$, and under field, $d_{h k l}(E)$ [26], equation 1:

$$
\varepsilon_{h k l}(E)=\frac{d_{h k l}(E)-d_{h k l}(\text { un })}{d_{h k l}(\text { un })} \quad \text { (Equation 1) }
$$




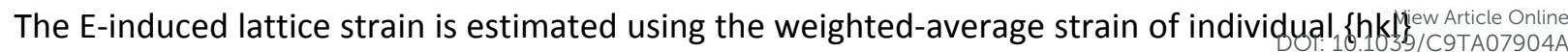
planes, $\varepsilon_{\mathrm{hkl}}$, as introduced by Daymond [27]:

$$
\varepsilon_{l a}=\frac{\sum_{h k l} T_{h k l} m_{h k l} \varepsilon_{h k l}(\beta)}{\sum_{h k l} T_{h k l} m_{h k l}(\beta)} \quad(\text { Equation 2) }
$$

where $\varepsilon_{\mathrm{hkl}}(\beta)$ is the strain along the direction parallel to the direction of $\beta$ for the $\{\mathrm{hkl}\}$ orientation, $T_{h k l}$ is the texture index, and $m_{h k l}$ are multiplicities of crystal $\{h k l\}$ planes. The materials are treated as a cubic structure with random grain texture, giving a $T_{\text {hkl }}$ value of 1 for any hkl. The $\mathrm{m}_{\mathrm{hkl}}$ values for $\{111\},\{200\}$ and $\{220\}$ crystal planes are 8,6 and 12 , respectively. $[15,28]$

The domain switching behaviour in polycrystalline ferroelectric ceramics leads to anisotropic dimensional deformation, as well as lattice strain. According to Jones and co-workers [20, 21, $28]$, the spontaneous strain for single crystal distortion associated with non- $180^{\circ}$ domain switching for a rhombohedral cell can be defined as follows:

$$
S=\frac{d_{111}-d_{\overline{1} 11}}{d_{\overline{1} 11}} \quad \text { (Equation 3) }
$$

The domain switching fraction for a single grain varies with grain orientation relative to the external electric field. Thus, the total value of extrinsic strain, $\varepsilon_{\mathrm{ds}}$, is obtained using integrated strain calculated over a range of grain orientations, $0^{\circ}<\beta<90^{\circ}$, as shown in equation 4 [28].

$$
\varepsilon_{d s}=S \int_{0}^{2 / \pi}\left[m \eta \cos ^{2}(\beta)\right] \sin (\beta) d \beta \quad \text { (Equation 4) }
$$

where $S$ is spontaneous strain, $m$ is multiplicity, $\eta$ is volume fraction of switched domains and $\beta$ is the grain orientation relative to the external electric field. XRD patterns for each azimuthal section are obtained via in-situ poling experiments to determine the peak intensities and peak position. $\eta$ for the $R 3 c$ phase is calculated using Jones' method $[20,28]$.

By this means, the intrinsic (lattice strain) and extrinsic (domain switching) contributions to the total macroscopic strain can be calculated in principle. In the present investigation, it was found that it was not possible to estimate the relative domain fractions in the rhombohedral phase as a function of grain orientation or electric field level, since the individual peaks associated with the (111) and (111) reflections were not clearly distinguished. Therefore, the weighted-average (Daymond) method was adopted instead, using Equation 2 in order to estimate the total macroscopic strain from the representative $\{111\}_{p},\{200\}_{p}$ and $\{220\}_{p}$ peak profiles.

The variations in the $\{111\}_{p},\{200\}_{p}$ and $\{220\}_{p}$ peak profiles under the application of two cycles of electric field for $0.7 \mathrm{BF}-0.3 \mathrm{BT}$ at $\beta=0$ and $90^{\circ}$ are shown in Figure 4 . All three peaks at $\beta=$ $0^{\circ}$ appear as doublets, corresponding to mixed-phase coexistence. Under application of an electric field, peaks shift to lower and higher $2 \theta$ parallel and perpendicular to the electric field direction, respectively but there is no further peak splitting, indicating the absence of an Einduced transformation. The $d$-spacing (d) and full width at half maximum (FWHM) for $\{111\}_{p}$ and $\{200\}_{p}$ XRD reflections at $\beta=0^{\circ}$ under electric field are shown in Figure S3 (Supplementary information). During two cycles, the $d_{111}$ and $d_{200}$ values increase with increasing amplitude of electric field, indicating a lattice expansion along the applied electric field direction. In undoped BF-BT, $\{111\}_{p}$ and $\{200\}_{p}$ peaks exhibit cyclic broadening under the influence of the 
applied electric field (Figure S3, Supplementary information), most likely indicating some nangüiew Article Online to mesoscale growth of domains.

The effective strain of $\{111\}_{p},\{200\}_{p}$ and $\{220\}_{p}$ peaks for BF-0.3BT are shown in Figure 4(c-e). Here, the individual strains, $\varepsilon_{111}, \varepsilon_{200}$ and $\varepsilon_{220}$ are calculated using peak positions, yielding strain anisotropy with $\varepsilon_{200}>\varepsilon_{220}>\varepsilon_{111}$ at $\beta=0$ and $90^{\circ}$. The effective strain at $\beta=0^{\circ}$ reaches approximately $\varepsilon \sim 0.20 \%$ at $60 \mathrm{kV} \mathrm{cm}^{-1}$. At $\beta=90^{\circ}$, the negative effective strain is obtained approximately half of the magnitude of the positive strain, $\varepsilon \sim 0.09 \%$. The E-induced lattice strains, calculated based on equation 2 , are $+0.18 \%$ and $-0.08 \%$ at $\beta=0$ and $90^{\circ}$, respectively. Compared with the directly-measured macroscopic S-E results (Figure $4 \mathrm{f}$ ), the positive strain $(+0.18 \%)$ is close to that of the peak-to-peak strain $(0.16 \%)$. Similar results were obtained for 0.7BF-0.3BT-0.005NLN ceramics, as illustrated in Figure S4 (Supplementary information) but with slightly high strains $(+0.20 \%)$.
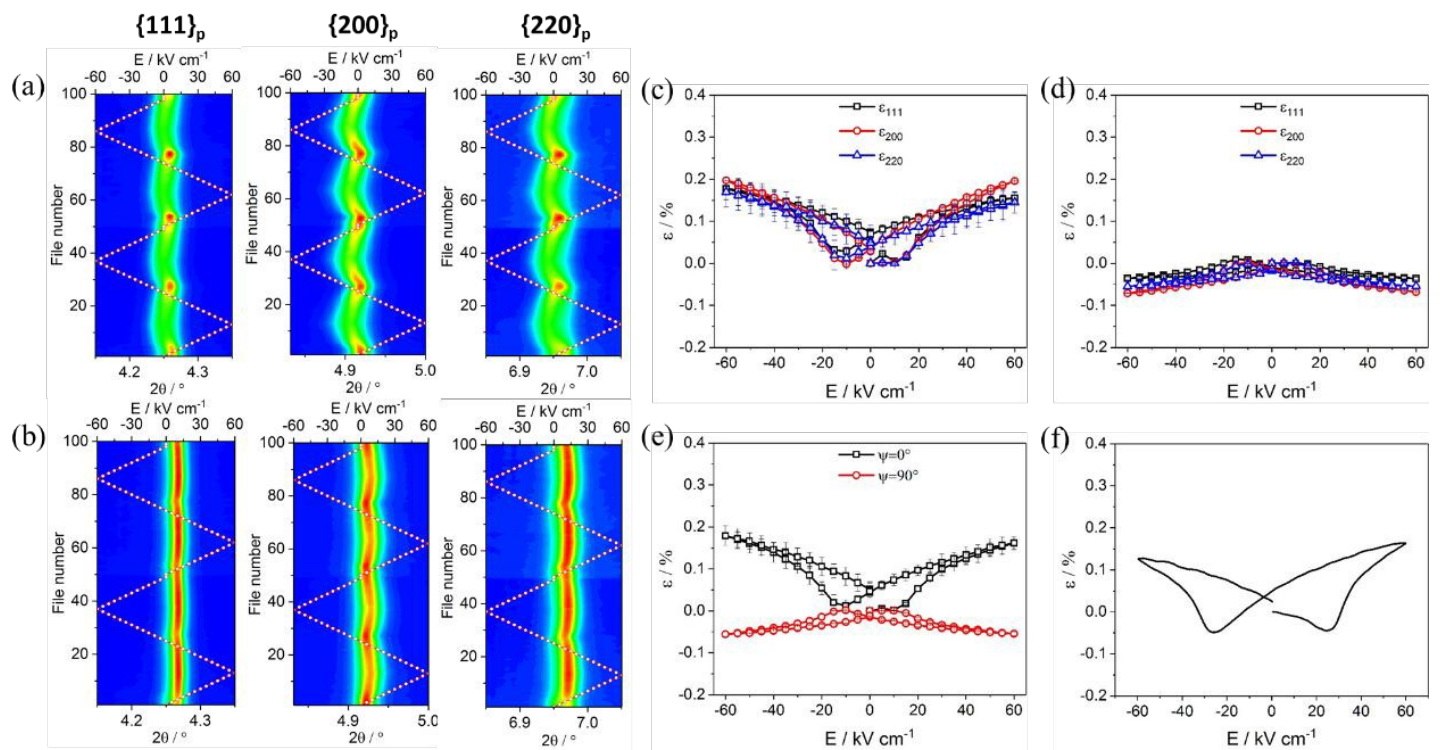

Figure 4. Contour plots of the $\{111\}_{p},\{200\}_{p}$ and $\{220\}_{p}$ peak profiles at (a) $\beta=0^{\circ}$ and (b) $\beta=$ $90^{\circ}$ obtained from the in-situ XRD experiment for BF-0.3BT, with two cycles of electric field poling under $\pm 60 \mathrm{kV} \mathrm{cm}^{-1}$; effective lattice strains calculated from representative peaks with grain orientation for (c) $\beta=0^{\circ}$ and (d) $\beta=90^{\circ}$ for BF-0.3BT; (e) The E-induced lattice strains for $\beta=0^{\circ}$ and $\beta=90^{\circ}$ for BF-0.3BT; (f) directly measured macroscopic S-E loop for BF-0.3BT.

For $x=0.01$, only single peaks are observed in the unpoled state which remain during and after application of the electric field. However, the peak positions shift with external electric field for all representative peaks during two cycles, Figure 5. The $\{111\}_{p}$ and $\{200\}_{p}$ XRD peak profiles at $E=0$ and $E=60 \mathrm{kV} \mathrm{cm}^{-1}$, as well as calculated $d$-spacing and FWHM for $\{111\}_{p}$ and $\{200\}_{p}$ XRD reflections at $\beta=0^{\circ}$ under electric field are shown in Figure 6. During two cycles, the $d_{200}$ changes more significantly than $d_{111}$ with increasing amplitude of electric field. As illustrated in Figure 5, the FWHM values for $\{111\}_{p}$ and $\{200\}_{p}$ XRD reflections remain almost constant during application of the electric field but the large electrostrain would nonetheless result in the development of some microstresses at grain boundaries. These however, are anticipated to be lower than in a material which undergoes a field induced transition from relaxor to long range ferroelectric order. 

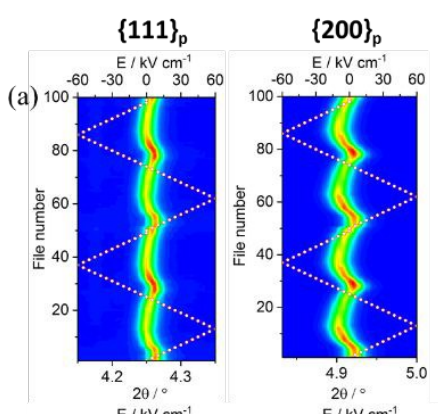

$\{220\}_{p}$
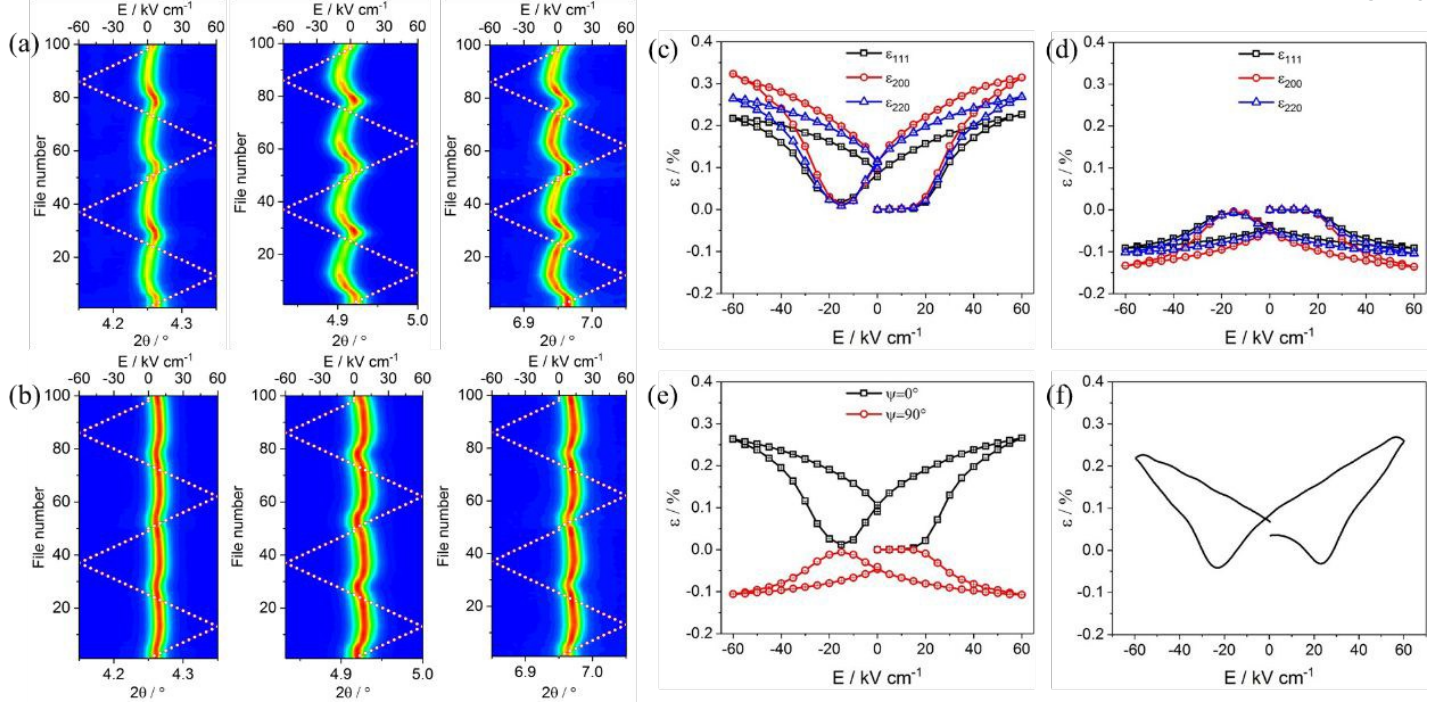

Figure 5. Contour plots of the $\{111\},\{200\}$ and $\{220\}$ peak profiles at (a) $\beta=0^{\circ}$ and (b) $\beta=90^{\circ}$ obtained from the in-situ XRD experiment for BF-0.3BT-0.01NLN, with two cycles of electric field poling under $\pm 60 \mathrm{kV} \mathrm{cm}^{-1}$; effective lattice strains calculated from representative peaks with grain orientations of (c) $\beta=0^{\circ}$ and (d) $\beta=90^{\circ}$ for BF-0.3BT-0.01NLN; (e) The E-induced lattice strain strain for $\beta=0^{\circ}$ and $\beta=90^{\circ}$ for BF-0.3BT; (f) directly measured macroscopic S-E loop for BF-0.3BT-0.01NLN.

The individual strains, $\varepsilon_{111} \sim 0.32 \%, \varepsilon_{200} \sim 0.26 \%$ and $\varepsilon_{220} \sim 0.21 \%$ obtained at $\beta=0^{\circ}$ for BF-BT$0.01 \mathrm{NLN}$ under an electric field of $60 \mathrm{kV} \mathrm{cm}^{-1}$ exhibit strain anisotropy, with the E-induced lattice strain strains of $+0.28 \%$ at $\beta=0^{\circ}$ and $-0.12 \%$ at $\beta=90^{\circ}$, similar to that determined from directly measured S-E loops ( 0.27\%) (Figure 5f). Negative strains, $\mathrm{S}_{\text {neg }} \sim 0.03 \%$ and $\mathrm{S}_{\text {rem }} \sim$ $0.08 \%$, are still evident, indicating a small contribution from the minor $R 3 \mathrm{C}$ phase but suggesting that the majority of strain arises from distortion of the pseudocubic phase. For $\mathrm{x}=$ 0.02 , qualitatively similar data to $x=0.01$ were obtained, as illustrated in Figure S5 (Supplementary information).

(a)
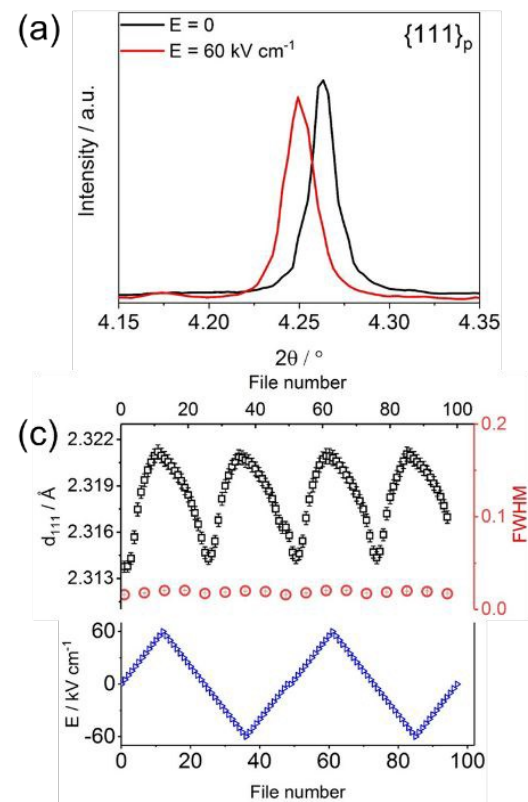

(b)

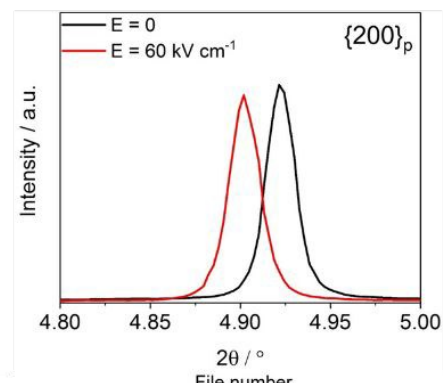

(d)

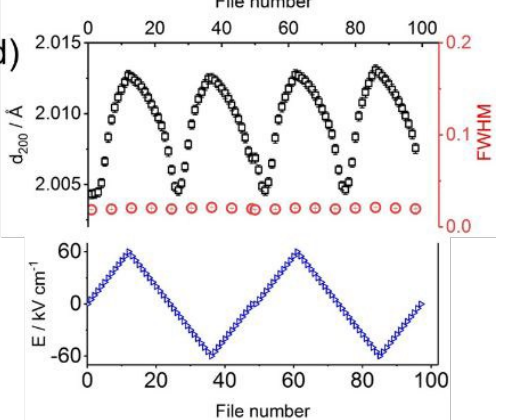


Figure 6. (a) $\{111\}_{p}$ and (b) $\{200\}_{p}$ XRD peak profiles under 0 and $60 \mathrm{kV} \mathrm{cm}^{-1}$; d-spacing and dew Article Online FWHM of (c) $\{111\}_{p}$ and (d) $\{200\}_{p}$ XRD peak profiles at $\beta=0^{\circ}$ obtained from the in-situ XRD experiment for BF-0.3BT-0.01NLN, with two cycles of electric field poling under $\pm 60 \mathrm{kV} \mathrm{cm}^{-1}$.

BF-0.3BT-0.03NLN refines to a single pseudocubic structure prior to and after poling with less significant peak shifts under electric field (Figure 7). The d-spacing and FWHM for $\{111\}_{\mathrm{p}}$ and $\{200\}_{p}$ XRD reflections for $\beta=0^{\circ}$ under electric field are shown in Figure S6 (Supplementary information). Compared to other compositions, only small variations in $d_{111}$ and $d_{200}$ without any changes in FWHM are observed. The E-induced lattice strains are $\sim+0.08 \%$ and $-0.03 \%$ for compressive and tensile directions (Figure 6), which are consistent with the directly measured S-E results.
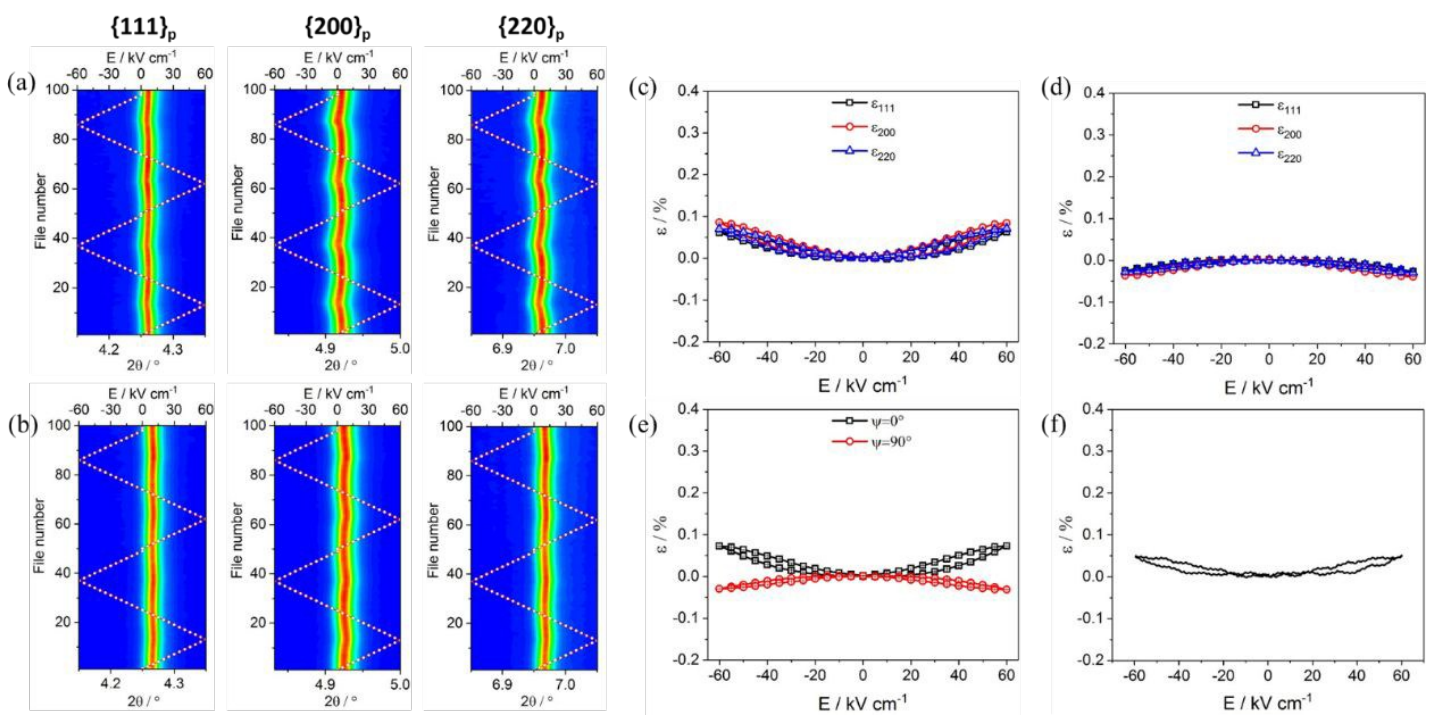

Figure 7. Contour plots of the $\{111\},\{200\}$ and $\{220\}$ peak profiles for (a) $\beta=0^{\circ}$ and (b) $\beta=90^{\circ}$ obtained from the in-situ XRD experiment for BF-0.3BT-0.03NLN, with two cycles of electric field poling under $\pm 60 \mathrm{kV} \mathrm{cm}^{-1}$; effective lattice strains calculated from representative peaks with grain orientations of (c) $\beta=0^{\circ}$ and (d) $\beta=90^{\circ}$ for BF-0.3BT-0.03NLN; (e) The E-induced lattice strain for $\beta=0^{\circ}$ and $\beta=90^{\circ}$ for BF-0.3BT-0.03NLN; (f) directly measured macroscopic S-E loop for BF-0.3BT-0.03NLN.

The absence of an apparent E-induced long-range FE state during in-situ measurements at 60 $\mathrm{kV} \mathrm{cm}{ }^{-1}$ is potentially due to an insufficiently large applied field to overcome the local distortions of the lattice relating to the charge/strain distributions of the constituent ions. In particular, the A-site contains $\mathrm{Ba}\left(\mathrm{r}_{\mathrm{Ba}}=1.61 \AA\right)$ and $\mathrm{Bi}\left(\mathrm{r}_{\mathrm{Bi}}=1.32 \AA\right)$ ions which are not only dissimilar in size but which also have fundamentally different (ionic and covalent, respectively) bonding with respect to $O$ ions in the cuboctahedral interstice.[29] Consequently, ultra-high field measurements ( $150 \mathrm{kV} \mathrm{cm}^{-1}$ ) were performed on BF-BT-0.01NLN which exhibited the largest strain at $60 \mathrm{kV} \mathrm{cm}^{-1}$ to determine whether long-range ferroelectric order could be detected.

\section{$\underline{\text { In-situ ultra-high electric field poling XRD }\left(150 \mathrm{kV} \mathrm{cm}^{-1}\right)}$}

The variations in the representative $\{111\}_{p},\{200\}_{p}$ and $\{220\}_{p}$ peak profiles, along with the external electric field direction $\left(\beta=0^{\circ}\right)$ is illustrated as $3 D$ contour maps in Figure 8 . No peak broadening and splitting is observed in the three single peaks prior to, during or after poling, 
confirming again that no macroscopic E-induced structural transformation occurs up to 150 jew Article Online $\mathrm{kV} \mathrm{cm}^{-1}$.
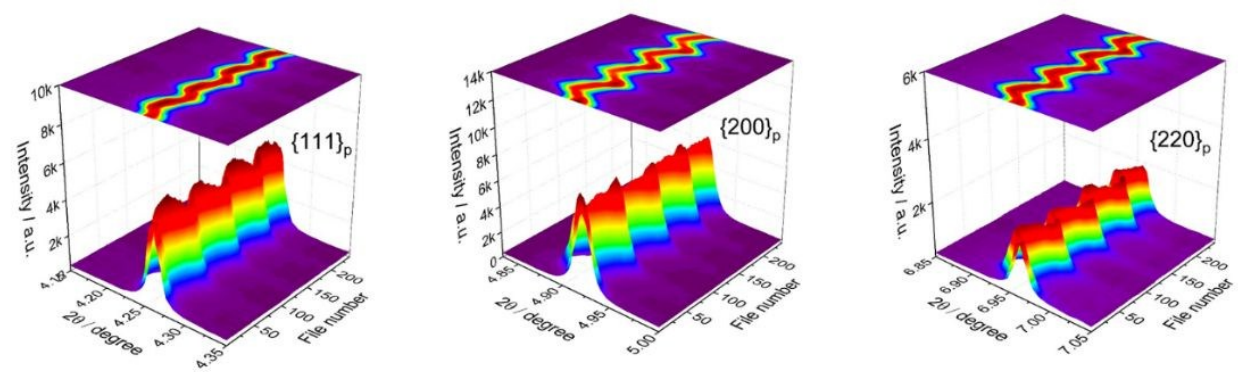

Figure 8. Surface contour plots to illustrate changes in the $\{111\}_{p},\{200\}_{p}$ and $\{220\}_{p}$ XRD peak profiles (at $\beta=0^{\circ}$ ) for BF-BT-0.01NLN under application of 2 cycles of electric field of \pm 150 $\mathrm{kV} \mathrm{cm}{ }^{-1}$.

The individual lattice strains and the E-induced lattice strain for BF-BT-0.01NLN obtained from the shifts in these peak profiles are shown in Figure 9, for 6 complete cycles of the alternating electric field. At $150 \mathrm{kV} \mathrm{cm}^{-1}$, the highest strain values of $\varepsilon_{111}, \varepsilon_{200}$ and $\varepsilon_{220}$ at $\beta=0^{\circ}$ are $\sim 0.54 \%$, $0.74 \%$ and $0.58 \%$, respectively, exhibiting strain anisotropy, $\varepsilon_{200}>\varepsilon_{220}>\varepsilon_{111}$, qualitatively consistent with data obtained at $60 \mathrm{kV} \mathrm{cm}^{-1}$. The highest E-induced lattice strain was $\sim 0.64 \%$ at $150 \mathrm{kV} \mathrm{cm}^{-1}$ for BF-BT-0.01NLN.
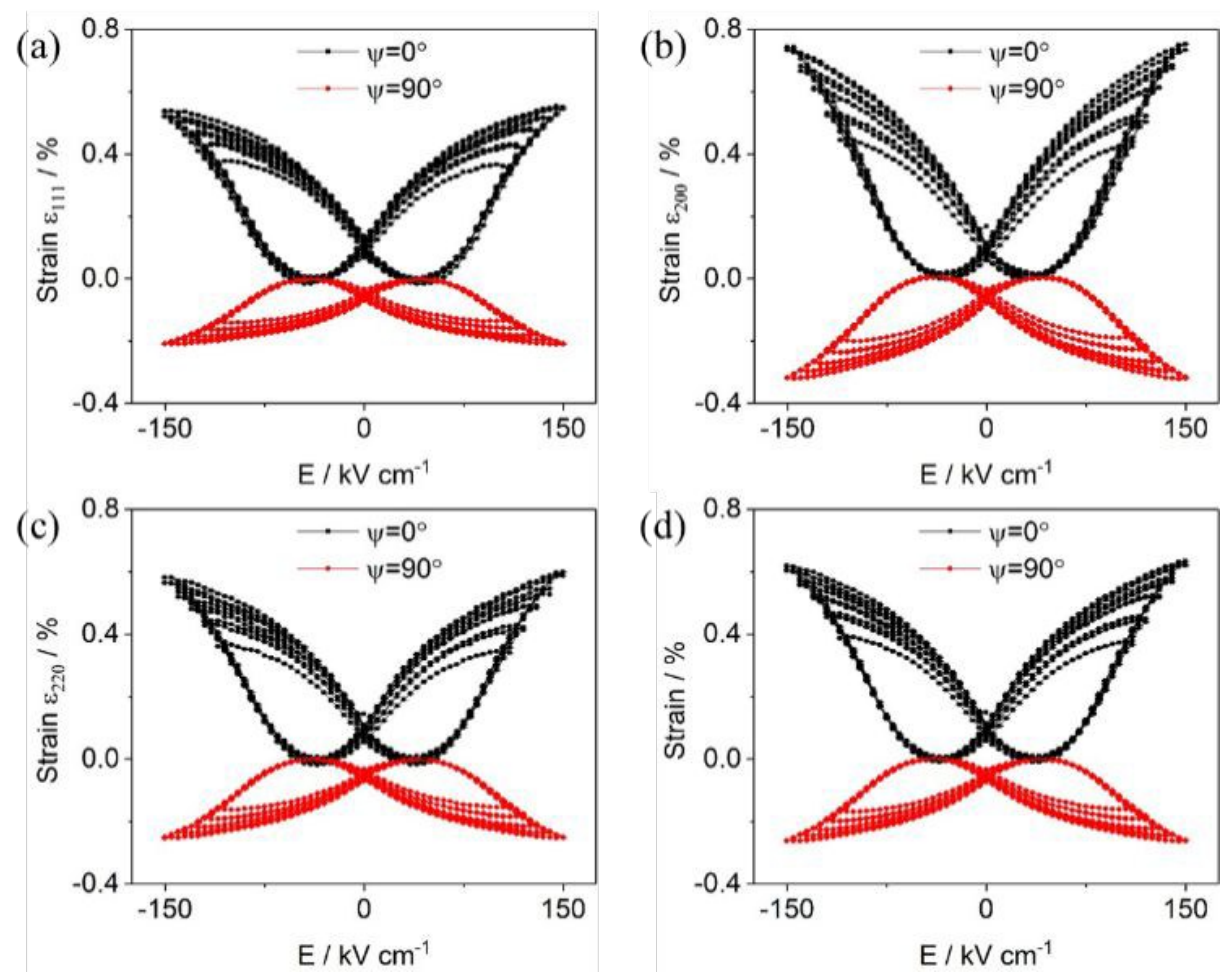

Figure 9. Effective lattice strains calculated from single peak profiles of (a) $\{111\}_{p}$ (b) $\{200\}_{p}$ (c) $\{220\}_{p}$ peaks and (d) The E-induced lattice strain of BF-0.3BT-0.01NLN up to $150 \mathrm{kV} \mathrm{cm}^{-1}$ at $\beta=0$ and $90^{\circ}$. 
For lead-based [30-37] and lead-free piezoceramics, [4-8, 16-18, 38-55] dopants are often used to induce a relaxor state which, under an applied electric field undergoes an irreversible or reversible transformation into a metastable FE phase [56]. For example, an irreversible phase transition from RFE cubic to metastable FE rhombohedral/tetragonal phase can be induced in NBT-based materials which subsequently exhibit FE behaviour after removing the external electric field. [57-60] It is evident from the in-situ data presented here that the BF-BT based compositions investigated during the present study do not follow this general trend and no long-range FE state is induced during or after application of the applied electric field.

Previous authors have suggested that the stability of the initial RFE cubic state may be attributed to insufficient field to induce a long-range $\mathrm{FE}$ state but here electric fields with amplitude up to $150 \mathrm{kV} \mathrm{cm}^{-1}$ have been applied to the NLN-doped BF-BT ceramics without the appearance of peak broadening, narrowing or splitting. It is evident therefore that these BFBT solid solutions are more resistant towards E-induced structural transitions to a long-range FE state than typical lead-based and lead-free relaxor compositions. Nonetheless, extremely large strains are achieved. These two contradictory data points (no field induced transition/large strain) can only be explained by considering that the BF-BT compositions undergo significant local distortions that do not propagate through the lattice within a single symmetry but whose polarisation vectors approximately align in the direction of the applied field. We note that in compositions with $x=0.01$, unlike undoped compositions, no cyclic broadening is observed under the action of applied electric field, indicating the absence of significant nano- to mesoscale domain growth.

Disruption of long-range order is primarily attributed to the large difference in ionic radius between $\mathrm{Ba}^{2+}$ and $\mathrm{Bi}^{3+}$ ions, further enhanced by a third perovskite component in the solid solution $\left(\mathrm{Nd}\left(\mathrm{Li}_{1 / 2} \mathrm{Nb}_{1 / 2}\right) \mathrm{O}_{3}\right)$. The strain anisotropy of the diffraction peaks $\left(\varepsilon_{200}>\varepsilon_{220}>\varepsilon_{111}\right)$, particularly evident at $150 \mathrm{kV} \mathrm{cm}^{-1}$, lends credence to this structural model, suggesting there are multiple nanodomain symmetries within a nominally pseudocubic lattice which distort approximately in the direction of the applied field but in different crystallographic directions and with different magnitudes. We note however, that a tetragonal phase appears dominant as the 200 peak shows the largest shift. Figure 10 is a schematic which illustrates how pseudosymmetry even at large applied fields is maintained within a grain. For simplicity, the schematic is restricted to rhombohedral, orthorhombic and tetragonal symmetries but the symmetry will be dictated by the local chemistry and the direction of the applied field with respect to the grain orientation.

Strain anisotropy of $\varepsilon_{200}>\varepsilon_{211}>\varepsilon_{220}>\varepsilon_{111}$ has previously been observed in $\mathrm{BF}-\mathrm{K}_{0.5} \mathrm{Bi}_{0.5} \mathrm{TiO}_{3}-$ $\mathrm{PbTiO}_{3}$ and attributed to the existence of local tetragonal polar nano-regions. [19] Similar distributions of $A$-site cation radii exist in $\mathrm{BF}^{-} \mathrm{K}_{0.5} \mathrm{Bi}_{0.5} \mathrm{TiO}_{3}-\mathrm{PbTiO}_{3}\left(\mathrm{r}_{\mathrm{K}}=1.64 \AA\right.$ and $\mathrm{r}_{\mathrm{Pb}}=1.49 \AA$ ) to those in BF-BT along with mixed ionic and covalent bonding.[29] Moreover, Levin, Reaney and co-workers [61] propose that such mixtures form an ideal environment for the creation of an 'active' solid solution, further adding that such effects could be enhanced by the substitution of large B-site ions $\mathrm{Mg}^{2+}\left(r_{\mathrm{Mg}}=0.72 \AA\right)$ and $\mathrm{Sc}^{3+}\left(r_{\mathrm{sc}}=0.745 \AA\right)$ on the B-site.[29] We note that preliminary in-situ studies of high electrostrain $\mathrm{BiScO}_{3}$ and $\mathrm{BiMg}_{2 / 3} \mathrm{Nb}_{1 / 3} \mathrm{O}_{3}$ doped $\mathrm{BF}-\mathrm{BT}$, first presented by Murakami et al $[6,8]$, reveal that no long-range FE phase is induced, while the strain anisotropy is similar to that of NLN-doped compositions. (Figure S7 and S8, Supplementary information) Here, the in-situ poling experiments coupled with simple 
crystallochemical arguments provide a compelling case for our proposed E-indycedjew Article Online pseudosymmetric structure model.

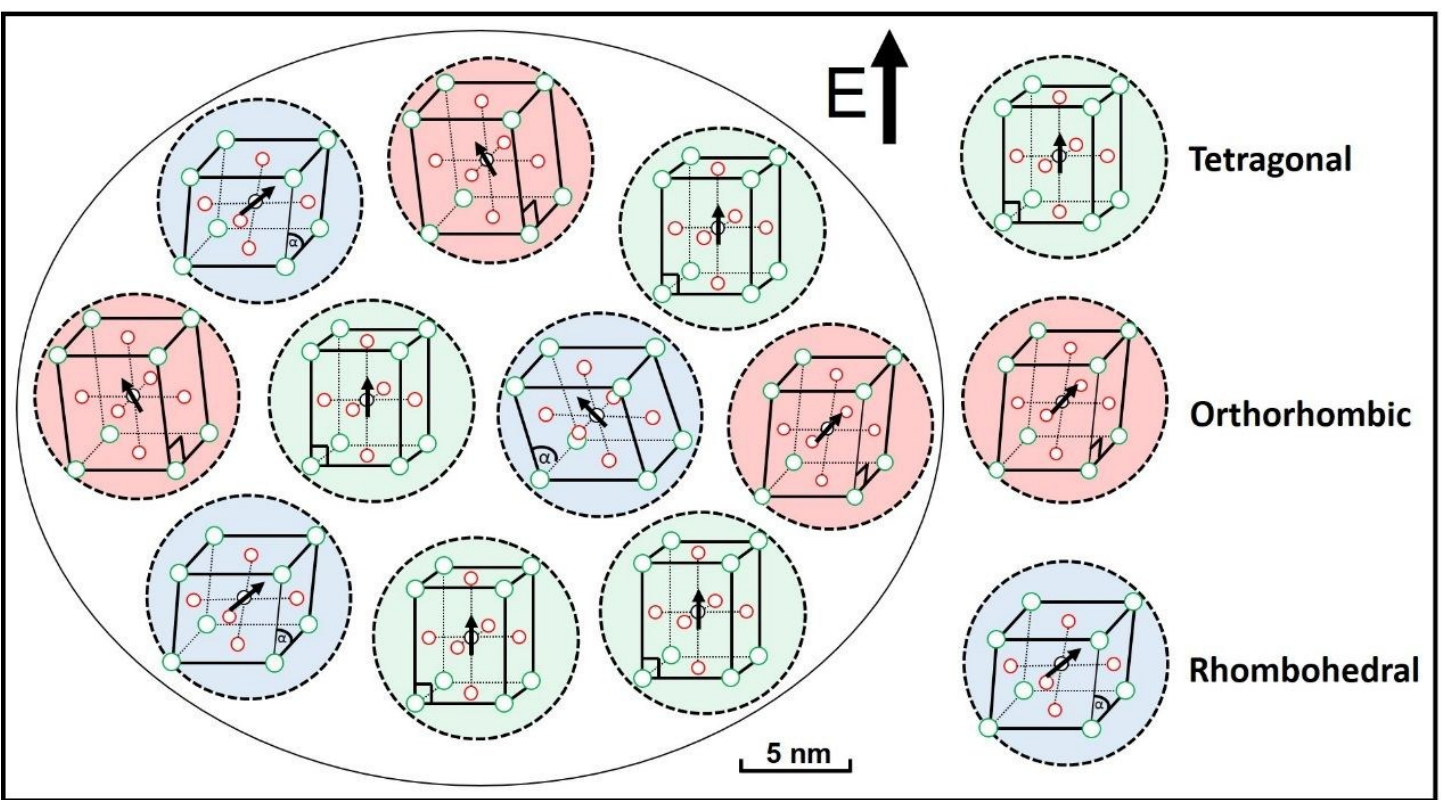

Figure 10. A schematic illustration explaining the formation of a high strain E-induced pseudosymmetric state. Local distorted regions are shown as, but are not limited to, rhombohedral, tetragonal and orthorhombic symmetries.

\section{Conclusions}

A phase transition from a mixed-phase FE (rhombohedral) and RFE (cubic) to single RFE (cubic) occurs in BF-BT-XNLN as $x$ increases, as evidenced by changes in Rietveld refinement data, $\mathrm{P}-\mathrm{E}, \mathrm{S}-\mathrm{E}, \mathrm{LCR}$ permittivity and domain morphology. In-situ XRD revealed that, even at $150 \mathrm{kV}$ $\mathrm{cm}^{-1}$, BF-BT-NLN does not exhibit a transition to a long-range ordered FE state despite the large strains recorded for this system. Instead, an E-induced pseudosymmetric model is proposed in which local regions distort approximately in the direction of the applied field but adopt a range of symmetries, dictated by the local composition and the orientation of the grain with respect to the applied field. This model not only explains the large strains in these highly active solid solutions but also the strain anisotropy $\left(\varepsilon_{200}>\varepsilon_{220}>\varepsilon_{111}\right)$. It is proposed that the formation of an active pseudosymmetric solid solution in BF-BT ceramics with high electrostrain follows precepts proposed by Levin, Reaney and co-workers [61] in which large ionically bonded $\mathrm{A}$-site ions $\left(\mathrm{Ba}^{2+}\right)$ disrupt displacements of the smaller covalently bonded $\mathrm{Bi}$ ions. Identical behaviour is observed in $\mathrm{BiScO}_{3}$ and $\mathrm{BiMg}_{2 / 3} \mathrm{Nb}_{1 / 3} \mathrm{O}_{3}$ doped $\mathrm{BF}-\mathrm{BT}$ ceramics previously which exhibit electrostrain $>0.4 \%$, suggesting that this is a general phenomenon that applies to many perovskite structured relaxors with a large spread of ionic radii on the Aand B-sites.

\section{Acknowledgements:}

We thank the EPSRC for funding (Substitution and Sustainability in Functional Materials and Devices, EP/L017563/1 and Synthesizing 3D Metamaterials for RF, Microwave and THz Applications, EP/N010493/1) and Diamond Light Source for access to beamline I15 (proposal 
number EE19590-1) that contributed to the results presented here. Additionally, we thank View Article Online Tim. P. Comyn (Ionix Advanced Technologies) for assistance with sample preparation. JLJ acknowledges the U.S. National Science Foundation award number DMR-1409399. 


\section{References}

1. G. Catalan and J. F. Scott, Adv. Mater., 2009, 21, 2463.

2. J. Rödel, W. Jo, K. T. P. Seifert, E-M. Anton, T. Granzow and D. Damjanovic, J. Am. Ceram. Soc., 2009, 92, 1153.

3. D. Wang, G. Wang, S. Murakami, Z. Fan, A. Feteira, D. Zhou, S. Sun, Q. Zhao and I. M. Reaney, J. Adv. Dielectr., 2018, 8, 1830004.

4. D. Wang, Z. Fan, D. Zhou, A. Khesro, S. Murakami, A. Feteira, Q. Zhao, X. Tan and I. M. Reaney, J. Mater. Chem., A. 2018, 6, 4133.

5. D. Wang, Z. Fan, W. Li, D. Zhou, A. Feteira, G. Wang, S. Murakami, S. Sun, Q. Zhao, X. Tan and I. M. Reaney, ACS Appl. Energy Mater., 2018, 1, 4403.

6. S. Murakami, N. T. A. F. Ahmed, D. Wang, A. Feteira, D. C. Sinclair and I. M. Reaney, J. Eur. Ceram. Soc., 2018, 38, 4220.

7. W. Gao, J. Lv and X. Lou, J. Am. Ceram. Soc., 2018, 101, 3383.

8. S. Murakami, D. Wang, A. Mostaed, A. Khesro, A. Feteira, D. C. Sinclair, Z. Fan, X. Tan and I. M. Reaney, J. Am. Ceram. Soc., 2018, 101, 5428.

9. S. O. Leontsev and R. E. Eitel, J. Mater. Sci., 2011, 26, 9.

10. S. Kim, G. P. Khanal, H-W. Nam, M. Kim, I. Fujii, S. Ueno, C. Moriyoshi, Y. Kuroiwa and S. Wasa, J. Cera. Soc. Jpn., 2018, 126, 316.

11 I. Fujii, R. Lizuka, Y. Nakahira, Y. Sunada, S. Ueno, K. Nakashima, E. Magome, C. Moriyoshi, Y. Kuroiwa and S. Wada, Appl. Phys. Lett., 2016, 108, 172903.

12. I. Calisir, A. A. Amirov, A. K. Kleppe and D. A. Hall, J. Mater. Chem. A., 2018, 6, 5378.

13. J. Filik, A.W. Ashton, P.C.Y. Chang, P.A. Chater, S.J. Day, M. Drakopoulos, M.W. Gerring, M.L. Hart, O.V. Magdysyuk, S. Michalik, A. Smith, C.C. Tang, N.J. Terrill, M.T. Wharmby and H. Wilhelm, J. Appl. Crystallogr., 2017, 50, 959.

14. Diffrac Plus TOPAS v. 3.0 (Manual), BRUKER AXS GmbH, Karlsruhe, 2006.

15. L. Daniel, D. A. Hall, J. Koruza, K. G. Webber, A. King and P. J. Withers, J. Appl. Phys., 2015, 117, 174104.

16. D. Wang, A. Khesro, S. Murakami, A. Feteira, Q. Zhao and I. M. Reaney, J. Eur. Ceram., Soc. 2017, 37, 1857.

17. I. Calisir and D. A. Hall, J. Mater. Chem. C., 2018, 6, 134.

18. G. Wang, J. Li, X. Zhang, Z. Fan, F. Yang, A. Feteira, D. Zhou, D. C. Sinclair, T. ma, X. Tan, D. Wang and I. M. Reaney, Energy Environ. Sci., 2019, 12, 582.

19. Y. Li, Z. Zhang, Y. Chen and D. A. Hall, Acta Mater., 2019, 160, 199.

20. Y. Li, Y. Chen, Z. Zhang, A. Kleppe and D. A. Hall, Acta Mater.,2019, 168, 411.

21. J. L. Jones, E. B. Samovich and K. J. Bowman, J. Appl. Phys.,2005, 97, 034113. 
22. D. A. Hall, T. Mori, P. J. Withers, H. Kungl, M. J. Hoffmann and J. Wright, Mater. Sci, View Article Online Technol.,2008, 24, 927.

23. D. A. Hall, A. Steuwer, B. Cherdihirunkorn, T. Mori and P. J. Withers, Acta Mater.,2006, 54, 3075.

24. D. A. Hall, S. Steuwer, B. Cherdhirunkorn, P. J. Withers and T. Mori, Mater. Sci. Eng. A., 2005, 409, 206.

25. D. A. Hall, A. Steuwer, B. Cherdhirunkorn, T. Mori and P. J. Withers, J. Appl. Phys., 2004, 96, 4245.

26. M.C. Ehmke, N.H. Khansur, J.E. Daniels, J.E. Blendell and K.J. Bowman, Acta Mater., 2014, 66,340 .

27. M.R. Daymond, J. Appl. Phys., 2004, 96, 4263.

28. J. E. Daniels and T. R. Finlayson, J. Appl. Phys., 2007, 101, 094104.

29. R. D. Shannon, Acta Cryst.,1976, A32, 751.

30. B. Narayan, J. S. Malhotra, R. Pandey, K. Yaddanapudi, P. Nukala, B. Dkhil, A. Senyshyn and R. Ranjan, Nature, 2018, 17, 427.

31. D. Wang, M. Cao and S. Zhang, Phys. Status Solidi RRL, 2012, 6, 135.

32. D. Wang, M. Cao and S. Zhang, J. Am. Ceram. Soc., 2011, 94, 3690.

33. Y. Li, D. Wang, W. Cao, B. Li, J. Yuan, D. Zhang, S. Zhang and M. Cao, Ceram. Int., 2015, 41, 9647.

34. Y. Li, J. Yuan, D. Wang, D. Zhang, H. Jin and M. Cao, J. Am. Ceram. Soc., 2013, 96, 3440.

35. D. Wang, M. Cao and S. Zhang, J. Am. Ceram. Soc., 2012, 95, 3220.

36. D. Wang, M. Cao and S. Zhang, J. Eur. Ceram. Soc., 2012, 32, 441.

37. D. Wang, M. Cao and S. Zhang, J. Eur. Ceram. Soc., 2012, 32, 433.

38. A. Khesro, D. Wang, F. Hussain, D.C. Sinclair, A. Feteira and I.M. Reaney, Appl. Phys. Lett., 2016, 109, 142907.

39. A. Zeb, D. A. Hall, Z. Aslam, J. Forrester, J. F. Li, Y. Li, C. C. Tang, G. Wang, F. Zhu and S. J. Milne, Acta Mater., 2019, 168, 100.

40. J. Hao, B. Shen, J. Zhai, C. Liu, X. Li and X. Gao, J. Appl. Phys., 2013, 113, 114106.

41. W. Jo, T. Granzow, E. Aulbach, J. Rodel and D. Damjanovic, J. Appl. Phys., 2009, 105, 094102.

42. J. Yao, W. Ge, L. Yan, W. T. Reynolds, J. Li, D. Viehland, D. A. Kiselev, A. L. Kholkin, Q. Zhang and H. Luo, J. Appl. Phys.,2012, 111, 064109.

43. D. Maurya, A. Pramanick, K. An and S. Priya, Appl. Phys. Lett.,2012, 100, 172906.

44. W. Jo, J. Daniels, D. Damjanovic, W. Kleemann and J. Rodel, Appl. Phys. Lett., 2013, 102, 192903. 
45. D. Maurya, A. Pramanick, M. Feygenson, J. C. Neuefeind, R. J. Bodnar and S. Priya,d. View Article Online Mater. Chem. C., 2014, 2, 8423.

46. Z. Fan, C. Zhou, X. Ren and X. Tan, Appl. Phys. Lett.,2017, 111, 252902.

47. Z. Fan, J. Koruza, J. Rodel and X. Tan, Acta. Mater., 2018, 151, 253.

48. Z. Fan and X. Tan, J. Eur. Ceram. Soc., 2018, 38, 3472.

49. Z. Fan and X. Tan, Appl. Phys. Lett., 2019, 114, 212901.

50. W. Li, Z. Xu, R. Chu, P. Fu and G. Zang, J. Am. Ceram. Soc., 2010, 93, 2942.

51. W. Li, Z. Xu, R. Chu, P. Fu and G. Zang, Mater. Lett., 2010, 64, 2325.

52. W. Li, Z. Xu, R. Chu, P. Fu and G. Zang, Physica B., 2010, 405, 4513.

53. J. Yin, G. Liu, X. Lv, Y. Zhang, C. Zhao, B. Wu, X. Zhang and J. Wu, J. Mater. Chem. A., 2019, 7, 5391.

54. J. Yin, G. Liu, C. Zhao, Y. Huang, Z. Li, X. Zhang, K. Wang and J. Wu, J. Mater. Chem. A., 2019, 7, 13658

55. C. Zhao, B. Wu, K. Wang, J-F. Li, D. Xiao, J. Zhu and J. Wu, J. Mater. Chem. A., 2018, 6, 23736.

56. Dittmer R. PhD thesis. University of Darmstadt, 2013.

57. G. Wang, D. A. Hall, T. P. Comyn, L. Daniel and A. K. Kleppe, J. Adv. Appl. Ceram., 2016, $115,89$.

58. G. Wang, D. A. Hall, Y. Li, C. A. Murray and C. C. Tang, J. Eur. Ceram. Soc., 2016, 36, 4015.

59. G. Wang, Y. Li, C. A. Murray, C. C. Tang and D. A. Hall, J. Am. Ceram. Soc., 2017, 100, 3293.

60. G. Wang, Z. Lu, Z. Zhang, A. Feteira, C. C. Tang and D. A. Hall, J. Am. Ceram. Soc., 2019, 00, 1-9.

61. I. Levin, W. J. Laws, D. Wang and I. M. Reaney, Appl. Phys. Lett., 2017, 111, 212902. 